\title{
What's So Special About Intergenerational Knowledge Transfer? Identifying Challenges of Intergenerational Knowledge Transfer
}

Studies on diversity topics and knowledge management abound in the management literature. However, we still know little about the impact of generational diversity on knowledge transfer. This is surprising, given that particularly the transfer of knowledge between employees who differ substantially in terms of their age is of increasing relevance to organisations: unless firms manage to stimulate intra-organizational knowledge transfer, the knowledge of retiring employees will be lost. This conceptual study first systematically reviews the empirical literature on intergenerational knowledge transfer. Second, the study integrates research on knowledge transfer and generational diversity in order to develop a theoretical framework and set of propositions addressing the specific challenges of intergenerational knowledge transfer.

Keywords: ageing workforce, diversity, knowledge transfer, organisational learning (JELcodes: M14, M50, M53, J14, J71)

\section{Introduction}

Studies on diversity topics and knowledge management abound in the management and psychology literature. Research has focused on either different aspects of knowledge transfer (e. g. Foss, Minbaeva, Pedersen, \& Reinholt, 2009) or differences between generations in the workplace (e. g. Lyons \& Kuron, 2013). However, research that combines these two fields is still limited. From a knowledge management perspective, scholars have explored antecedents (e. g. interpersonal trust, examined by Lee, Gillespie, Mann, \& Wearing, 2010; Mooradian, Renzl, \& Matzler, 2006), and potential outcomes (e. g. performance, examined by Levine \& Prietula, 2012) of knowledge transfer. Furthermore, scholars have demonstrated that potential obsta-

* Xenia Schmidt, M.A. (corresponding author): Trier University, Department of Business Administration, FB IV, Universitätsring 15, 54286 Trier, Germany. Email: Schmidtx@uni-trier.de.

Univ.-Prof. Dr. Katrin Muehlfeld: Trier University, Department of Business Administration, FB IV, Universitätsring 15, 54286 Trier, Germany. Email: Muehlfeld@uni-trier.de; additional affiliation: Utrecht University, Utrecht University School of Economics.

We would like to thank the editors of Management Revue, Associate Professor Susanne Gretzinger and Assistant Professor Simon Fietze, as well as two anonymous reviewers for their excellent guidance on how to improve the manuscript.

** Article received: September 20, 2016.

Article accepted: April 28, 2017. 
cles such as conflicts (Chen, 2011) can reduce the exchange of information between individuals.

Scholars in the field of diversity have looked at age-heterogeneous teams, and how younger and older individuals are distinct from each other (e. g. Costanza, Badger, Fraser, Severt, \& Gade, 2012). For instance, younger generations appear to have a stronger learning orientation; they prefer learning new skills and handling new situations compared to older generations (D'Amato \& Herzfeldt, 2008). Other findings revealed that these differences might also hinder the interaction between employees due to increased potential for conflicts (Jehn, Northcraft, \& Neale, 1999).

Although prior research has reported evidence in each field, little attention has been paid to how specifically the fields of knowledge transfer and generational diversity are interrelated (Ellwart, Bündgens, \& Rack, 2013; Harvey, 2012; Noethen \& Voelpel, 2011). From a knowledge-based perspective, we seek to combine these two streams in order to address the question whether employees who participate in intergenerational knowledge transfer are confronted with different situations than employees who exchange information with same-generation colleagues (Lauring \& Selmer, 2012; Noethen, 2011; Noethen \& Voelpel, 2011).

Since research on this topic is still limited, the aim of this paper is to summarise results of empirical research on intergenerational knowledge transfer based on a systematic review of studies, which deal explicitly or implicitly with various aspects of intergenerational knowledge transfer (Table 1). Based on this review of the literature, and integrating the existing, still highly limited empirical literature that directly addresses intergenerational knowledge transfer with related insights from studies at the interface of the literature on age/generational diversity and on knowledge transfer (e. g. co-worker support is a topic discussed in both streams) we developed a set of propositions. Figure 1 demonstrates how the propositions were developed based on the three different streams of literature. Finally, we incorporated our propositions into an existing, comprehensive conceptual framework relating to knowledge transfer in general (Figure 2). In so doing, we adapted and extended the theoretical framework suggested by Wang and Noe (2010). 


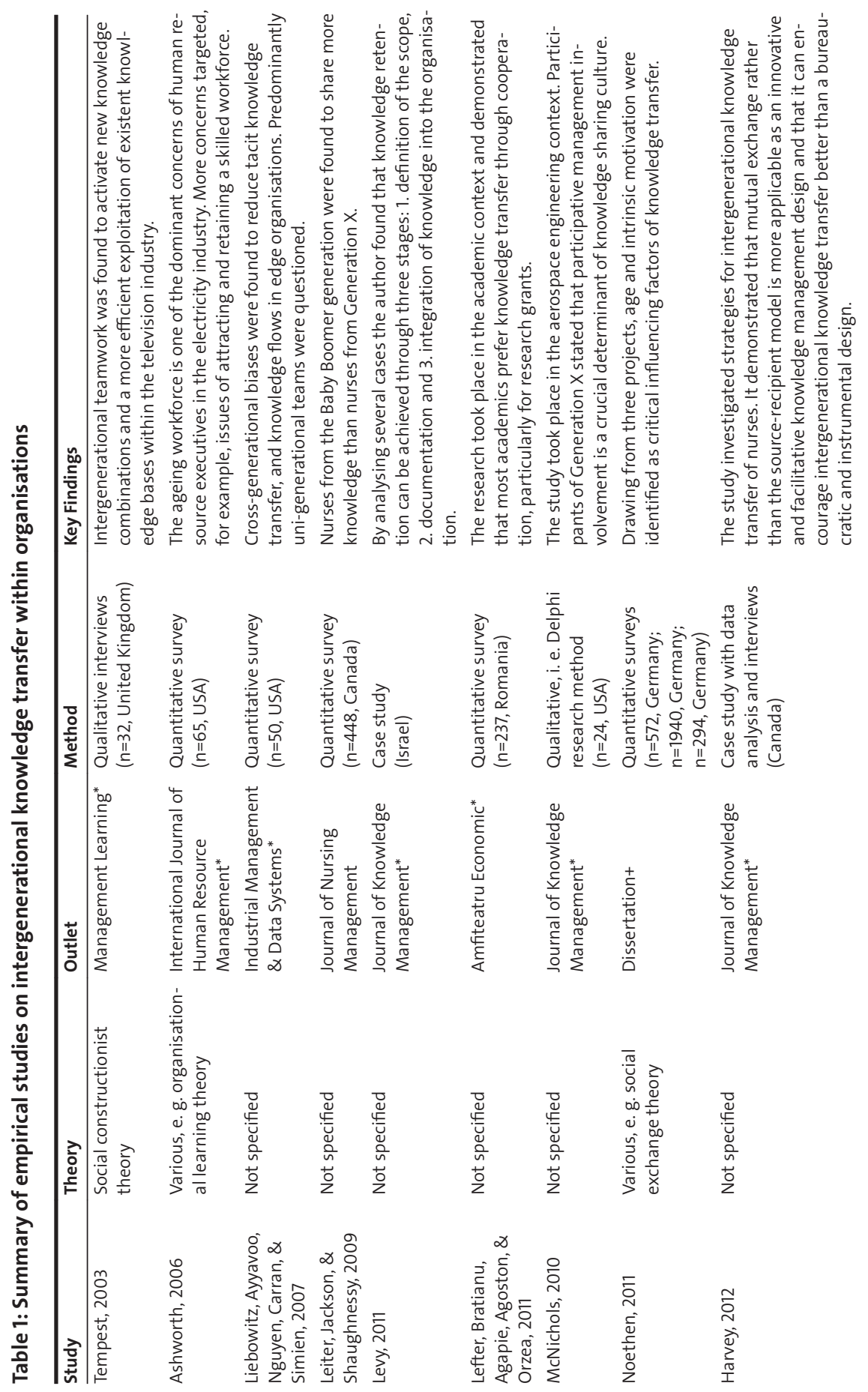




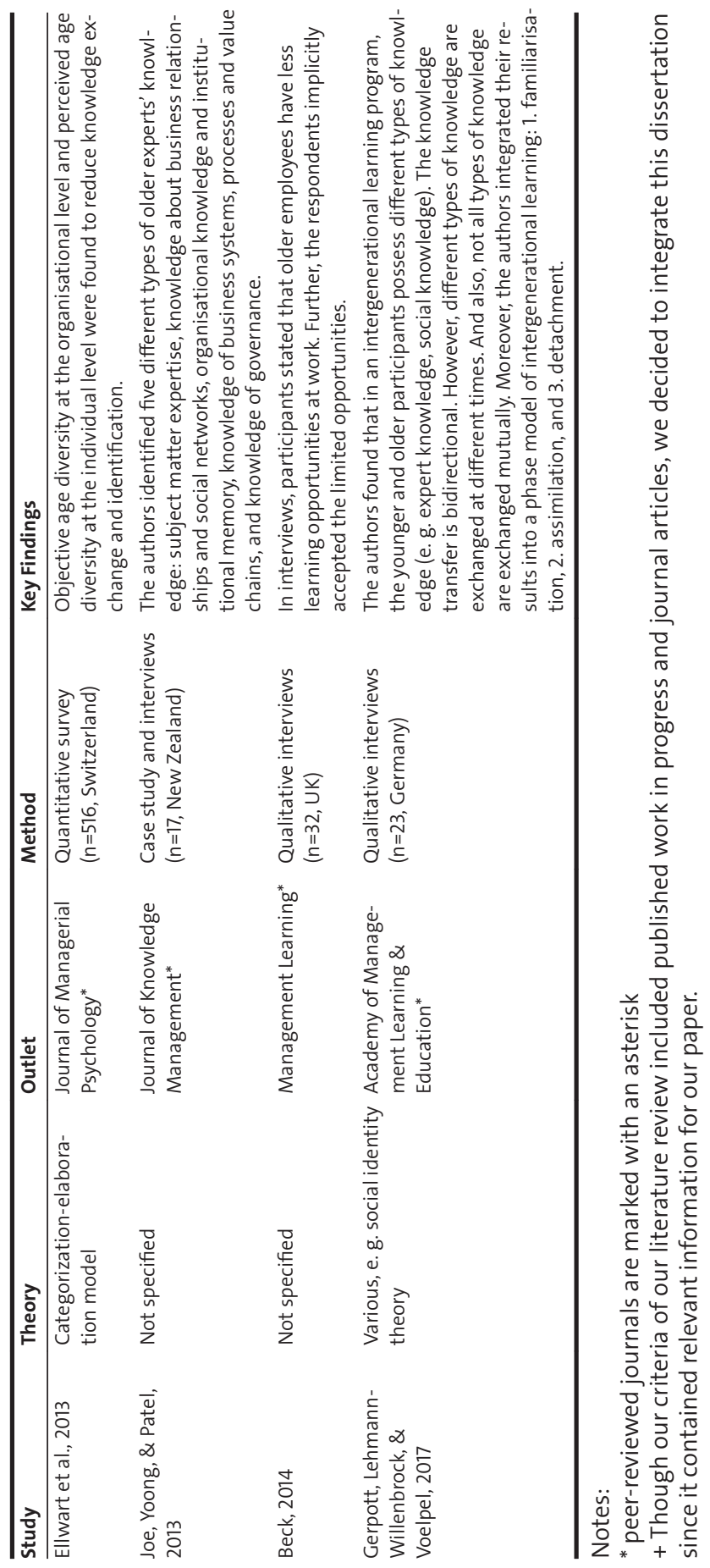


Figure 1: Propositions based on various streams of literature

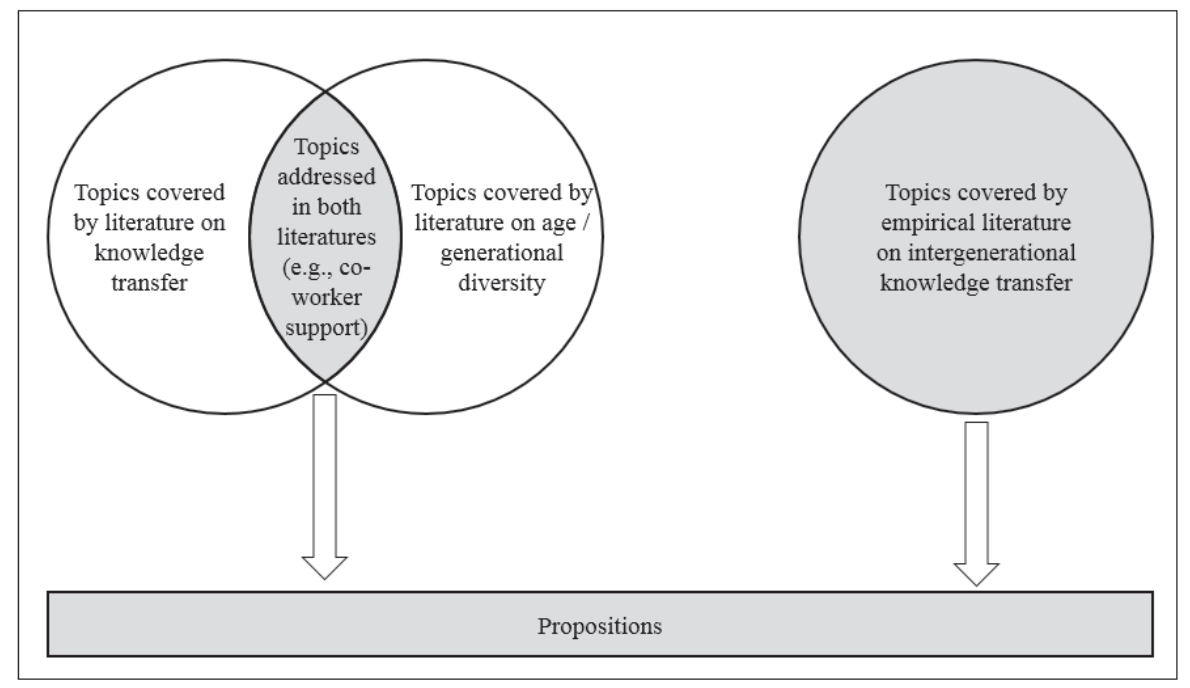

Therefore, our analysis is methodologically based on a two-step research process. First, we build our literature review on a search of eight major management/psychological databases with 21 keywords related to knowledge transfer and/or intergenerational aspects in organisations, such as 'knowledge transfer' and 'intergenerational contact'. A list of the keywords is provided in the appendix. We were inspired by the paper by Richter (2014) for our database selection because her article also focuses on demographic issues. We applied our keywords to the following databases: ISI Publica, IZA, Ifo Institute, JSTOR, Social Science Research Network (SSRN), EconStor, PsychINFO, and Econbiz. A selection of the databases have been used among published literature reviews as well (e. g. Burmeister \& Deller, 2016; Schneid, Isidor, Steinmetz, \& Kabst, 2016; van Wijk, Jansen, \& Lyles, 2008).

We, first, included studies that more or less explicitly addressed the topic of 'intergenerational knowledge transfer' and were empirical in nature. Second, because of the fairly small number of studies resulting from our first selection criterion, we additionally included studies that did not directly address the topic of intergenerational knowledge transfer but discussed related topics. We identified those related topics that we included in the development of our propositions by requiring them to have been investigated in both the literature on knowledge transfer and the literature on age/generational diversity (e. g. co-worker support).

Further, since willingness to engage in knowledge transfer provides an accurate prediction of actual behaviour (Schwaer, Biemann, \& Voelpel, 2012), we draw on studies that either address actual behaviour related to knowledge transfer or the willingness to engage in knowledge transfer. The database search process took place in 
June - November 2015. ${ }^{1}$ Second, we conducted a complementary search guided by a snowball procedure where we manually checked reference lists (Schneid et al., 2016). The snowball approach was implemented continually until spring 2017.

The remainder of this paper is structured as follows: In the next section, we present the theoretical and empirical background on intergenerational knowledge transfer. Then, we discuss the antecedents of intergenerational knowledge transfer, for which we expect a (more) positive or negative effect in contrast to regular knowledge transfer. Only antecedents are presented that, according to our research, seem to differ from regular knowledge transfer. The paper concludes with a discussion and implications for future research and management practice.

\section{Background and Literature Summary}

While the importance of knowledge transfer between employees with a large age difference has grown for organisations in the last few years and has been discussed in business publications (e. g. Milligan, 2014), academic research has not kept pace (Burmeister \& Deller, 2016). In the near future, many organisations will be confronted with serious challenges due to the demographic transition. In many developed countries, demographic transition implies that societies are ageing and that, for instance, in 2050 one third of the population in Germany is estimated to be aged 65 and over (OECD, 2014). These changes will affect individuals, societies, and, in particular, organisations (Calo, 2008; De Long, 2004; Drabe, Hauff, \& Richter, 2015; Kulik, Ryan, Harper, \& George, 2014).

The age structure of the labour market will change, and so will the age structure within organisations, with a growing number of older employees relative to younger ones. The resulting changes in the age-mix within organisations are quite likely to influence as well as the ways in which organisational members interact with each other (Calo, 2008; Kuhn \& Hetze, 2009; Noethen, 2011; Noethen \& Voelpel, 2011). Furthermore, employees of the high-birthrate cohort Baby Boomer will retire in the coming years (Macky, Wong, Gardiner, Lang, \& Coulon, 2008). For organisations, the near-simultaneous retirement of large numbers of employees implies a significant threat of losing valuable knowledge.

Drawing on the knowledge-based perspective, such a development can have tremendous consequences for organisations (Calo, 2008; De Long, 2004; Grant, 1996). The knowledge-based perspective has its roots in the resource-based view of the firm (Grant, 1996). The resource-based view postulates that firms possess particular (scarce) resources, competencies, and capabilities which lead to a competitive advantage (Pfeffer \& Salancik, 1978; Spender, 1996). Resources are, for example,

1 We additionally cross-checked the databases Scopus, Science Direct, Web of Science and EBSCO in February 2017. We applied the key terms 'intergenerational knowledge' transfer and 'intergenerational learning' as they are widely used in the title and keyword selection of articles on intergenerational knowledge transfer (e. g. Harvey, 2012). 
skilled employees (Wernerfelt, 1984). While the resource-based view distinguishes between a variety of important resources, such as machine capacity (Wernerfelt, 1984), the knowledge-based perspective regards knowledge as the most important resource an organization may have (Grant, 1996), because it is a fundamental requirement for progress and economic success in a knowledge-intense society (Argote \& Ingram, 2000; Grant, 1996; Noethen, 2011; van Wijk et al., 2008; Wang $\&$ Noe, 2010). Hence, knowledge constitutes a key source of competitive advantage for organisations.

Here, in accordance with the dominant view in organisational studies, knowledge is defined as being "created and organised by the very flow of information, anchored on the commitment and beliefs of its holder" (Nonaka, 1994, p. 15). The most common distinction between different forms of knowledge is the distinction between explicit and tacit knowledge (Alavi \& Leidner, 2001; Osterloh \& Frey, 2000; Polanyi, 1969). Explicit knowledge, which can be characterised as 'knowing about', refers to formal and standardised knowledge and can be codified and transferred more easily. For example, engineering knowledge of machine building can be categorised as explicit knowledge because it can easily be codified. Tacit knowledge captures 'knowing how', which is based on experience and action and therefore is hard to formalise and communicate (Grant, 1996; Lee et al., 2010; Nonaka, 1994). For instance, tacit knowledge could be a particular problem-solving strategy, which engineers apply in the innovation process.

A loss of knowledge has a potentially severe, negative impact on organisations, due, for example, to financial costs for reconstructing lost knowledge (De Long, 2004). The threat of losing knowledge is particularly serious for tacit knowledge. Tacit knowledge is not easily transferable, because it is attached to employees, firm-specific, and difficult to imitate and export (Ambrosini \& Bowman, 2001). For example, an innovative engineering team can be regarded as a source of major competitive advantage of an organisation. The output of this engineering team, i. e. their explicit knowledge, could easily be captured and saved in a Wiki, through patents, and so on. However, the unique resource for the organisation may be explained by the procedural strategy of the engineers and not only by their past output. This tacit knowledge contributes to the firm's competitive advantage. Yet, it is considerably more difficult to capture and transfer this tacit knowledge (De Long, 2004).

In the literature, knowledge transfer is viewed as a preventive solution to the threat of losing both tacit and explicit knowledge (Argote \& Ingram, 2000; Foss et al., 2009). Knowledge transfer is a fundamental part of organisational learning which involves both individual and collective learning (Argote, Ingram, Levine, \& Moreland, 2000; Grant, 1996; Zhao \& Anand, 2009). Hence, knowledge transfer can be characterized as "the process through which one unit (e. g. group, department, or division) is affected by the experience of another" (Argote \& Ingram, 2000, p. 151) or in other words, knowledge transfer is a process of transferring information from 
one source to another (Argote \& Ingram, 2000; van Wijk et al., 2008; Wang $\&$ Noe, 2010). While recent research has proposed that knowledge $\operatorname{transfer}^{2}$ can be operationalized as the combination of sharing of knowledge and seeking knowledge (Foss et al., 2009; Noethen, 2011; van den Hooff \& de Ridder, 2004; Watson \& Hewett, 2006, 2006; Wilkesmann \& Virgillito, 2013), the majority of prior studies have focused solely or primarily on knowledge sharing (e. g. Cabrera \& Cabrera, 2005; Foss et al., 2009). Knowledge sharing captures facets of providing information and knowledge to a source, such as by explicitly showing procedures to colleagues, whereas knowledge seeking describes the obtaining of knowledge from others, such as by asking colleagues (Wilkesmann, Wilkesmann, \& Virgillito, 2009). Moreover, knowledge transfer can take place at various levels such as dyads, teams, and organisations (Alavi \& Leidner, 2001) and can occur through different channels, such as face-to-face or online (Wang \& Noe, 2010).

Here, our focus lies on dyadic face-to-face intergenerational knowledge transfer between employees from the same organisation. Knowledge transfer in organisations always implies a transfer at the individual level (Alavi \& Leidner, 2001), and dyadic transfer constitutes the most basic form of knowledge transfer. Moreover, prior literature suggests (e. g. De Long \& Davenport, 2003; Liu \& Liu, 2011) that for successfully transferring tacit knowledge, in particular, it is, face-to-face interaction that works best, compared to alternative forms of interaction such as, virtual interaction. Finally, drawing from the knowledge-based perspective, tacit knowledge is more important for organisations in terms of representing a source of competitive advantage, precisely, among others, because it is more difficult to transfer. Retaining it also represents by far the greater challenge for organisations faced with the demographic transition, compared to preventing a loss of explicit knowledge. Hence, dyadic face-to-face intergenerational knowledge transfer could, therefore, play a potentially important part in organisations' efforts to retain effectively the tacit knowledge that the Baby Boomers possess when retiring.

Current literature on knowledge transfer does not, usually, refer explicitly to issues related to age or generational aspects. Consequently, we interpret insights related to knowledge transfer in general as referring to 'regular' knowledge transfer, between organisational members of roughly the same age/generation, without any additional potential complications arising from a large age or generational difference between the involved individuals. 'Intergenerational knowledge transfer' can, in turn, be conceptualised as the exchange of information between two individuals (here: employees) with a large age difference (Harvey, 2012; Noethen \& Voelpel, 2011). In general, the transfer works bidirectionally; young employees transfer knowledge to

2 Some authors explicitly distinguish knowledge transfer from similar expressions like knowledge exchange (Wang \& Noe, 2010). However, in general, these terms are often used synonymously or in very similar ways (Harvey, 2012). We use the terms knowledge transfer and knowledge exchange interchangeably. If we refer to the sharing or seeking of knowledge, we explicitly use these terms. 
older employees and vice versa (Gerpott et al., 2017; Gerpott \& Voelpel, 2014). In terms of, for instance, digitisation, particularly younger employees might also share knowledge with older employees. Prensky (2001) introduced the terms 'digital natives' and 'digital immigrants' to conceptualise this situation. The younger generations are referred to as 'digital natives', who grew up with technology and intuitively speak the 'language of technology'. Older generations are, in turn, considered as 'digital immigrants', who face problems with learning new technology. In particular, with regard to relatively recent technological knowledge, older generations might benefit from the knowledge of younger employees. However, embedded in the context of the demographic transition, intergenerational knowledge transfer often albeit not always targets the sharing of knowledge by older employees, to the benefit of younger employees and the organisation (Burmeister, \& Deller, 2016). From this view, older generations can, for example, provide important social knowledge to younger employees and share information about how to best deal with workplace conflicts (Gerpott et al., 2017). In this study, we thus use the generic term 'knowledge transfer' to refer to intragenerational knowledge transfer; with respect to age/ generational differences, the term 'intergenerational knowledge transfer' or similar expressions, such as knowledge transfer in age-diverse contexts, are applied. Furthermore, as we zoom in on the context of the demographic transition, we conceptualise intergenerational knowledge transfer as a specific kind of intergenerational knowledge transfer, which focuses on the sharing of information by older employees towards younger employees, and the seeking of knowledge by younger employees from older employees.

We expect intergenerational knowledge transfer to differ from intragenerational knowledge transfer in terms of its positive and negative antecedents. This basic proposition is motivated by insights derived from two theoretical frameworks that are particularly important in relation to age/generational diversity: first, the multigenerational approach, and, second, life-span theory (Cogin, 2012).

The idea of the multigenerational approach is that a generation is a cohort of people who share common experiences of life events within some specific time frame, for instance, at similar ages. These experiences impact these individuals and create similarities in attitudes and behaviours (Cogin, 2012; Costanza et al., 2012). Currently, three different generations prevail in the job market: Baby Boomers, Generation X, and Generation Y. Baby Boomers represent the generation born between 1945 and 1964. This generation is characterised as being loyal to their organisations and with a high value of their job (Macky et al., 2008). Generation X captures individuals born between 1965 and 1981. This generation is portrayed as pessimistic and individualistic. They are not loyal to their organisation and appreciate a work-life balance that implies a greater emphasis on the 'life' dimension, compared to previous generations (Macky et al., 2008). Finally, Generation Y, born between 1982 and 2000 , is highly familiar with modern (information and communication) technology and therefore used to change and a flexible working environment. They are also de- 
scribed as willing to learn and open to new challenges (Becton, Walker, \& JonesFarmer, 2014; Macky et al., 2008; Smola \& Sutton, 2002). Yet, lifespan-theory describes that when individuals grow older, their personality adapts (Cogin, 2012; Jones \& Meredith, 1996) and implies that younger individuals have different attitudes and personalities than older individuals.

Given that the prior literature provides empirical support for each of these premises (e. g. Cogin, 2012; Jones \& Meredith, 1996), we follow the approach of Joshi, Dencker, Franz and Martocchio (2010) who acknowledged the debate about age versus generation effect and integrated the variety of theoretical lenses. In other words, we integrate studies on (a) generational differences and on (b) age diversity in our analyses about intergenerational knowledge transfer. We cannot draw any definitive conclusions as to whether the observed differences between younger and older individuals can be traced back to either age-related development or generational cohort effects (McAdams, de St. Aubin, \& Logan, 1993) since it is difficult to disentangle age and cohort effects (Rhodes, 1983). When we refer to older or younger employees, the affiliation to younger or older generations is always implicated and vice versa. Taking this into account, both theoretical paradigms highlight that younger and older individuals are different in terms of their attitudes and beliefs, whether the primary source of these differences is age or generation. In any case, what is relevant in the context of this study is that these variations may influence antecedents that affect participation in intergenerational knowledge transfer. Moreover, intergenerational knowledge transfer always implies a genuine heterogeneity which might invoke distinct effects compared to homogenous groups, such as frictions and conflicts (Jehn et al., 1999). We, therefore, expect that intergenerational knowledge transfer will be different from intragenerational knowledge transfer.

So far, there are only a few studies that explicitly focus on intergenerational knowledge transfer, which are summarised in Table 1. Literature shows that intergenerational knowledge transfer rests on mutual exchange (Harvey, 2012). Still, Baby Boomers have been found to share more knowledge than members from Generation X (Leiter et al., 2009). Also, different types of knowledge (Gerpott et al., 2017) and expertise (Joe et al., 2013) have been distinguished. Interestingly, although younger employees were also found to share knowledge with older employees, there were particular types of knowledge, for example, social knowledge, which was only shared by older employees towards younger employees (Gerpott et al., 2017). Ellwart and colleagues (2013) addressed the question of how objective age diversity at the organisational level and perceived age diversity at the individual level influenced knowledge exchange within teams and identification with a team and found a detrimental effect. Tempest (2003), on the other hand, described positive results of intergenerational teamwork which was found to activate new knowledge combinations and to raise exploitation of existent knowledge. 


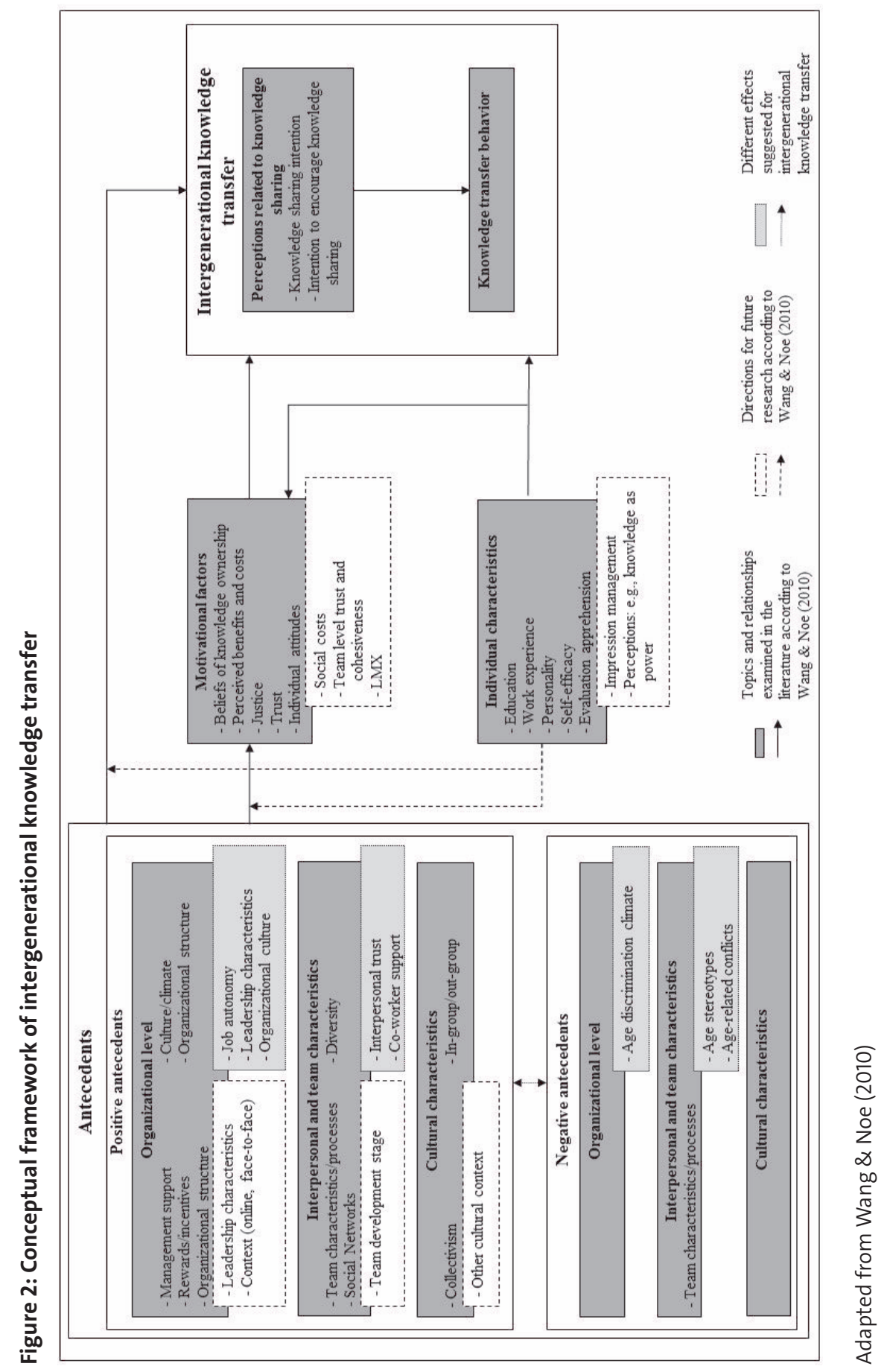


So while a nascent and promising literature has begun to address important questions related to intergenerational knowledge transfer many open questions remain. For instance, we are not aware of any study that specifically examines the question whether intergenerational knowledge transfer is different from regular knowledge transfer, and if so, in which ways. Hence, in developing a set of propositions for capturing differences in antecedents of inter- and intragenerational knowledge transfer, we integrated with this limited literature studies on knowledge transfer and age/generation diversity, and more generally, in as far as they overlapped in addressing related topics. The result is the conceptual framework shown in Figure 2.

\section{Propositions for a Conceptual Framework and Directions for Future Research}

Wang and Noe (2010) reviewed the literature on different aspects influencing knowledge transfer in general and developed a conceptual model based on this review of the literature. For instance, they considered environmental antecedents (categorised into organisational level characteristics, network characteristics, and cultural characteristics). Here, we adapted their framework by applying it to the specific setting of intergenerational knowledge transfer and by explicitly distinguishing between positive and negative antecedents.

In so doing, we focused on organisational level antecedents and network characteristics, given that we lacked literature that addressed aspects from a cultural perspective in one of the presented literature streams. We identified those antecedents based on our own literature review that (a) have been studied in a majority of studies on knowledge transfer and (b) that appear to have distinct effects on intergenerational vis-à-vis regular knowledge transfer.

For classifying individual antecedents as either organisational or network level, we followed the dominant classification in the reviewed literature. For example, van Wijk and colleagues (2008) categorised trust as a network level characteristic, and Wang and Noe (2010) looked at learning culture as an organisational level characteristic. Nonetheless, it may be possible to conceptualise some of the antecedents both at the organisational and the network level. For example, trust can be differentiated into interpersonal trust (van Wijk et al., 2008) and impersonal trust (Vanhala, Puumalainen, \& Blomqvist, 2011). Based on van Wijk and colleagues (2008) who investigated knowledge transfer in general and considered trust as a network characteristic, we also classified trust as a network characteristic, especially because none of the studies included in our review discussed trust (explicitly) at the organisational level. Moreover, we believe that a focus on trust as a network related variable is also consistent with our focus on face-to-face dyadic knowledge transfer. 


\section{Positive Antecedents to Intergenerational Knowledge Transfer}

Scholars in the literature on knowledge transfer, in general, have explored a variety of antecedents stimulating knowledge transfer. For example, job autonomy (e. g. Foss et al., 2009) was found to increase knowledge transfer. Characteristics of the organisation and social relationships have an influence on the knowledge exchange of employees (van Wijk et al., 2008; Wang \& Noe, 2010). From among this large number of organisational and network level antecedents that impact regular knowledge transfer, here, we zoom in on those factors that appear to show a different effect in age-diverse knowledge transfer compared to regular knowledge transfer, as suggested by our propositions.

\section{Organisational level characteristics}

Job autonomy. Job autonomy describes the opportunity a job provides for employees to individually plan their work and decide when they carry out their tasks (Hackman \& Oldham, 1976). In other words, it is at the discretion of employees to make decisions when and how to perform their assignments at their own pace (Dodd \& Ganster, 1996; Foss et al., 2009; Nonaka, 1994). This greater flexibility is associated with positive effects on employee attitudes. Employees with higher job autonomy show a more positive work motivation and higher job satisfaction (e. g. Hackman \& Lawler, 1971; Inceoglu, Segers, Bartram, \& Vloeberghs, 2009). By definition, autonomy also offers employees more opportunities to interact with colleagues and to exchange knowledge (Nonaka, 1994). Management research has pointed out that job autonomy is a highly relevant antecedent of knowledge sharing (Foss et al., 2009; Noethen, 2011; Noethen \& Voelpel, 2011), yet, does not appear to have any effect on knowledge seeking (Noethen, 2011). In a similar vein, Mueller (2014) found that employees who were explicitly allowed to dedicate time to knowledge sharing among project team members actually shared more knowledge. When explicitly encouraged in this way to share their knowledge and in response to this signal indicating the importance of such behaviour to the organisation, employees might engage in knowledge sharing that would otherwise not happen. Knowledge seeking is arguably less at risk of not taking place without such organisational support: If employees perceive the necessity to seek knowledge on a particular issue in order to be able to fulfil their job duties, they are more likely to take the initiative and seek this knowledge without receiving explicit support from the organisation.

Drawing from these findings and combining it with our definition of intergenerational knowledge transfer, we conceptualise that the effect of job autonomy is larger for intergenerational knowledge sharing than for regular knowledge sharing and smaller for intergenerational knowledge seeking than for regular knowledge seeking. Also, studies that focus on age-related differences complement our prediction. Inceoglu and colleagues (2009) and Inceoglu, Segers, and Bartram (2012) found that 
for older employees, job autonomy and flexibility on the job were more important than for younger employees. Extending these findings, we suggest that younger employees appreciate job autonomy less than older employees do. Following our definition of intergenerational knowledge transfer, older employees play a key role in knowledge sharing. Hence, it is very likely that job autonomy has an even larger effect on intergenerational knowledge sharing than on regular knowledge sharing. In contrast, younger employees do not only show lower preferences for job autonomy but they also mainly search for knowledge.

\section{Proposition 1a: For knowledge sharing, the positive effect of job autonomy is larger for intergenerational interactions than for intragenerational interactions.}

Proposition 1b: For knowledge seeking, the positive effect of job autonomy is smaller for intergenerational interactions than for intragenerational interactions.

Organizational culture. Prior research has identified organisational culture as an important antecedent to knowledge transfer. We interpret organisational culture as beliefs and attitudes in an organisation that help to deal with different issues of the organisation (Schein, 1984; Smircich, 1983). In other words, organisational culture represents the foundation of values and beliefs that can impact individual and organisational behaviour (Mueller, 2014). Organizational culture can embrace different aspects, such as supportive organisational culture and learning culture. Based on our literature review, the notion of a learning organisation emerged as particularly relevant.

The term 'learning culture' is often used to conceptualise an environment where most organisational members value learning and strive for high performance through learning (Jo \& Joo, 2011; Wei, Zheng, \& Zhang, 2011). Research on knowledge management has demonstrated that a high appraisal of learning in organisations enables knowledge sharing (Rhodes, Hung, Lok, Ya-Hui Lien, \& Wu, 2008; Jo \& Joo, 2011). Similar to this idea, subjective norms with respect to knowledge sharing also positively influence knowledge transfer (Cabrera \& Cabrera, 2005; Minbaeva \& Pedersen, 2010). Taken together, an environment that is characterised by a positive appreciation of learning appears to positively affect the exchange of knowledge. Here, we suggest that this effect will be even stronger for both intergenerational knowledge sharing and seeking, compared to intragenerational settings. This proposition rests on the following arguments, derived from our literature review:

Some scholars have explored learning oriented character traits among different generations (D'Amato \& Herzfeldt, 2008; Matzler \& Mueller, 2011). Learning oriented individuals favour the development of new skills and want to handle new situations. The process of learning itself is important to them, and they understand their capabilities to be flexible because they can be improved (D'Amato \& Herzfeldt, 2008; Matzler \& Mueller, 2011). Comparing younger and older generations, 
younger generations indicate higher scores in learning orientation; suggesting that learning norms might matter more for employees belonging to younger generations. A learning culture may stimulate young employees to request information from older employees and to expand their knowledge (knowledge seeking).

Furthermore, we expect that a learning culture enriches the knowledge sharing that older employees engage in, based on results of the age stereotypes literature. Studies on the effects of stereotypes have investigated the consequences of negative (Abrams, Crisp, Marques, Fagg, Bedford, \& Provias, 2008; Hess, Hinson, \& Statham, 2004; Hilton \& von Hippel, 1996) and positive age stereotype priming (Levy, Pilver, Chung, \& Slade, 2014). For instance, older adults who were primed with negative stereotypes showed a decrease in performance (Hess et al., 2004). Organizational learning culture could reduce the detrimental effects of stereotypes on older employees. When an organisational culture acknowledges the learning of its members, older employees, in particular, may perceive their expertise as valuable and may feel appreciated. This effect may be particularly powerful for older employees as they tend to have, in general, fewer learning opportunities at work than younger employees do (Beck, 2014). In conclusion, learning norms and learning orientation appear to have the potential to increase significantly the seeking of knowledge by young employees and to stimulate older employees to share their knowledge. ${ }^{3}$

Proposition 2: The effect of an organisation-wide learning culture is more important for stimulating intergenerational knowledge transfer than for facilitating regular knowledge transfer.

Leadership characteristics. An employee's perception of the leader and his/her leadership style appears to be a fundamental antecedent of knowledge transfer. Prior studies have suggested that certain types of leadership style may stimulate knowledge transfer particularly effectively. For instance, empowering leadership appears to predict an increase in knowledge sharing (Srivastava, Bartol, \& Locke, 2006; Xue, Bradley, \& Liang, 2011), presumably because it implies a behaviour where power is shared with subordinates, thereby increasing the intrinsic motivation of employees. Aspects of empowering leadership include, for instance, participative decision-making and information sharing (Srivastava et al., 2006).

Transformational leadership style is another type of leadership that appears to be positively associated with knowledge transfer in general. It involves shifts in the beliefs, needs, and values of the employees and is characterised by idealised influence, inspirational motivation, intellectual stimulation and individualised consideration (Bass, Waldman, Avolio, \& Bebb, 1987; Kuhnert \& Lewis, 1987). There is abun-

3 Finally, although this section focuses on antecedents, prior literature also discusses a reversed causality. Gerpott and Voelpel (2014) suggested that intergenerational knowledge transfer improves the learning culture in organizations. 
dant empirical evidence that supports positive effects of transformational leadership, for example, on organisational learning and innovation (García-Morales, LlorénsMontes, \& Verdú-Jover, 2008) or indirectly on team performance (Schaubroeck, Lam, \& Cha, 2007). Moreover, there is some tentative evidence that transformational leadership climate could invoke employees' intention to share knowledge, addressing the question of antecedents to knowledge transfer (Liu \& DeFrank, 2013). Taken together, leadership appears to be an important variable which may influence employees' knowledge transfer intention and behaviour (Liu \& DeFrank, 2013; Srivastava et al., 2006).

The question arises which role leadership behaviour plays in intergenerational knowledge transfer. To the best of our knowledge, there are no studies which have directly and explicitly analysed preferences for different leadership styles depending on age or generation. So far, research has offered only evidence that generations differ in their preferred character traits of leaders (Arsenault, 2004). For instance, Generation $\mathrm{X}$ and Generation $\mathrm{Y}$ favour determination and ambition in their leaders more strongly than Baby Boomers while Baby Boomers consider competence as particularly important. However, stimulating intergenerational knowledge transfer may represent a comparatively greater leadership challenge because employees of different ages/generations value distinct traits or behaviours in their leaders, and respond positively to them, for example, by effectively engaging in knowledge transfer. This would require leaders to exhibit a larger range of leadership behaviours in order to appeal to these employees belonging to different age groups/generations. Also, when seeking to facilitate intergenerational knowledge transfer, leaders may need to appeal to different motivations and hence may need to use different incentives to encourage younger vis-à-vis older employees to participate. While for intragenerational knowledge exchange, participants are relatively more likely to react positively to the same leadership style, stimulating intergenerational knowledge transfer may thus call for leaders to apply different leadership styles for younger versus older participants. All in all, we thus propose that:

Proposition 3: Stimulating intergenerational knowledge transfer through the adoption of certain leadership styles is more difficult compared to stimulating intragenerational knowledge transfer because it requires incorporating a more multi-faceted leadership style in order to appeal to all employees of different ages/generations.

\section{Network level characteristics}

Co-worker support. Many studies on knowledge transfer use social exchange theory as a theoretical background (Cabrera \& Cabrera, 2005; Wang \& Noe, 2010). We follow this approach and build our arguments on the premises of social exchange theory (Blau, 1964). One assumption of social exchange theory is that individuals adjust their relations with other people based on self-interest and a cost-benefit ana- 
lysis (Blau, 1964; Cook \& Whitmeyer, 1992). Individuals interact with each other because they expect, material or immaterial, reciprocal rewards in the future (Cabrera \& Cabrera, 2005; Wang \& Noe, 2010). Drawing on social exchange theory, coworker support might classify as a valuable antecedent that predicts knowledge transfer. Perceived co-worker support captures employees' perception of how much their co-workers, as a collective group, support and value their involvement (Swift \& Virick, 2013). Employees who perceive their co-workers to be supportive tend to assist them in return (Ladd \& Henry, 2000). In a similar vein, Collins and Smith (2006) found that a climate of trust for co-workers increased employees' belief that exchange and combination of knowledge will yield personal and organisational value, and also that they believe their colleagues were capable of exchanging and combining information.

Here, we suggest that the effect of co-worker support is larger for intergenerational knowledge sharing and smaller for intergenerational knowledge seeking compared to the corresponding processes between same-generation employees. In regular knowledge transfer, employees are more prone to share knowledge when they perceive their colleagues to be supportive (Cabrera \& Cabrera, 2005; Cabrera, Collins, \& Salgado, 2006; Lee, Yoo, \& Yun, 2015; Swift \& Virick, 2013).

Referring to intergenerational knowledge transfer, we first discuss prior research that has investigated how different generations value co-worker support. Bristow, Amyx, Castleberry, and Cochran (2011) found that members of Generation X valued working with friendly and helpful co-workers more than did members of Generation Y. Further, a related stream of research has investigated the value of social interactions in the work environment for members of different generations. For instance, Twenge, Campbell, Hoffman, and Lance (2010) demonstrated that employees belonging to the Baby Boomer generation place higher value on social interaction than employees belonging to Generation Y. Further, Sirias, Karp, and Brotherton (2007) explored the preference to work alone and discovered evidence that individuals of Generation X show a higher preference to work alone in contrast to Baby Boomers. Twenge (2010) summarised that younger generations prefer working alone more often. In addition, Benson and Brown (2011) have investigated the relationship between co-worker support and job satisfaction among Baby Boomers and Generation X. They found that co-worker support was a predictor of job satisfaction for Baby Boomers, but not for Generation X. Job satisfaction itself, in turn, was found to stimulate knowledge transfer (de Vries, van den Hooff, \& de Ridder, 2006).

In conclusion, there is some albeit not fully consistent evidence that employees belonging to younger generations are driven by a comparatively stronger preference to work alone and show a lower appreciation of co-worker support. Based on these findings, we propose that, for intergenerational knowledge sharing, co-worker support is relatively more important because, on the one hand, co-worker support is an 
important antecedent of knowledge sharing in general and on the other hand, because older employees express a comparatively stronger preference for co-worker support in contrast to younger employees. For the seeking of knowledge from older employees, we expect that the effect of co-worker support is weaker than for knowledge seeking from the same generational colleagues because younger employees favour co-worker support less.

Proposition 4: The effect of co-worker support is larger for intergenerational knowledge sharing than for regular knowledge sharing, and smaller for intergenerational knowledge seeking than for regular knowledge seeking.

Interpersonal trust. Another important network antecedent of knowledge transfer is trust. Trust can be characterised as the disposition of an individual to put oneself in a position of vulnerability to someone else (Mooradian et al., 2006; Swift \& Hwang, 2013). According to McAllister (1995), trust encompasses two components: affect- and cognition-based trust. Cognition-based trust describes a rational decision of whom and under which circumstances an individual develops trust. Affect-based trust is more emotionally based on individuals' belief in the genuine care and concern for their partners (McAllister, 1995; Schwaer et al., 2012). Trust embraces an individual's expectation of how another person will behave in the future (Renzl, 2008). ${ }^{4}$

For dyadic knowledge transfer, we focus on the network level of trust. Wilkesmann and colleagues (2009) describe knowledge transfer as a social dilemma situation where trust can reduce the potential risks involved in sharing and seeking knowledge. On the one hand, sharing knowledge might imply a loss of status and the hazard to become easily replaceable within the organisation, as other employees become more knowledgeable in the corresponding domain (Kankanhalli, Tan, \& Wei, 2005; Renzl, 2008). On the other hand, employees who ask colleagues for information might risk exposing themselves as lacking in expertise and thereby become vulnerable. Trust in a peer can decrease these anxieties (Renzl, 2008). Trust appears to increase the knowledge sharing of employees by reducing such risks (Fleig-Palmer \& Schoorman, 2011; Hsu \& Chang, 2014; Lin, 2007; Maurer, Bartsch, \& Ebers, 2011; Mooradian et al., 2006; van Wijk et al., 2008). Further, Watson and Hewett

4 Yet, trust can also be conceptualized at the organizational level, i. e. as impersonal trust, and therefore, target "the individual employee's expectations about the employing organization's capability and fairness" (Vanhala et al., 2011, p. 492). Impersonal trust showed a mediating effect between employees' perception of HRM practices and different types of organizational innovativeness (Vanhala \& Ritala, 2016). With tentative suggestions, impersonal trust might also be mediating the relationship between HR-practices related to knowledge transfer and intergenerational knowledge transfer. However, although it is conceivable that impersonal trust could influence intergenerational knowledge transfer, we are not aware of any study on impersonal trust that meets the inclusion criteria of our review. As such, we consider this to be an issue beyond the scope of this study, which could, however be very interesting to be addressed in future research. 
(2006) found that trust in the knowledge source plays a key role for the frequency of knowledge re-use. Interestingly, cognition-based trust and affect-based trust may lead to different results: Affect-based trust appears to predict knowledge sharing, while the results for cognition-based trust are not significant (Swift \& Hwang, 2013) - with the underlying reasons for these differential effects so far unaddressed.

Referring to intergenerational knowledge transfer, we propose that the effect of trust is positively related to knowledge sharing and knowledge seeking, yet, the effect is smaller than for intragenerational knowledge transfer. By definition, trust implies vulnerability to another person. The effects are particularly strong in intragenerational relationships. There is a risk that this vulnerability can be interpreted as losing one's power position due to sharing knowledge or by revealing oneself as not knowing relevant information. However, in intergenerational relationships, direct competition is smaller as employees are generally more likely to be at different stages of their careers (Pelled, Eisenhardt, \& Xin, 1999). Older employees may be less afraid of losing power or status by sharing experiences with younger employees vis-à-vis sharing them with colleagues of their same age. Therefore, because vulnerability is less of an issue, lower levels of trust are needed for intergenerational knowledge transfer than for intragenerational knowledge transfer. Also, since age and, consequently, generational affiliation are positively related to job experiences (Noethen, 2011; Pelled et al., 1999), it is generally expected that employees belonging to younger generations possess less job-related expert knowledge. Therefore, the risk of exposing oneself as inexperienced is less pronounced when younger employees seek knowledge from older ones than it is in intragenerational knowledge transfer.

Further, from a generational perspective, studies by Trzesniewski and Donnellan (2010) and Robinson and Jackson (2001) found supporting evidence that today's generations show lower levels of trust, in general. As trust is predominantly lower for younger generations, this argument may relate to intergenerational knowledge transfer as well.

Taken together, younger individuals who receive knowledge from older individuals may need lower levels of trust compared to a situation where they seek knowledge from younger employees. The risk of exposing themselves as lacking in knowledge is smaller in this situation, unlike it would be for knowledge seeking from same-generation employees. Also, younger employees are unlikely to pose a significant career risk to older employees, who share their knowledge with them. Therefore, we expect trust to be less important as a facilitator of knowledge transfer in intergenerational settings, compared to intragenerational ones.

Proposition 5: The positive effect of trust on knowledge transfer is smaller, the larger the age difference is between participants. 


\section{Negative Antecedents to Intergenerational Knowledge Transfer}

Compared to enabling factors, obstacles to knowledge transfer have attracted comparatively less attention. Nevertheless, a few scholars have investigated factors that might harm knowledge transfer. For example, knowledge ambiguity and knowledge stickiness (i. e. sticky information that is difficult to transfer) were shown to decrease knowledge transfer (Sheng, Chang, Teo, \& Lin, 2013). Particularly for intergenerational knowledge transfer, we suggest that barriers can be expected to prevail at both the organisational level and interpersonal level. Prior literature that has looked into reasons for the malfunctioning of intergenerational interactions has identified attitudes, for example, stereotypes, and behaviours, such as discrimination, as potential drivers (Joshi et al., 2010; Starks, 2013). In accordance with this differentiation, we identified three main negative antecedents for intergenerational knowledge transfer: perceived age discrimination climate, age stereotypes, and agerelated conflicts.

\section{Organisational level characteristics}

Perceived age discrimination climate. While discrimination, in general, can be defined as "a situation in which individuals identical in regard to their productive ability are treated differently because of certain of their nonproductive characteristics" (Büsch, Dahl, \& Dittrich, 2009, p. 633) and therefore could also apply at the interpersonal level, perceived age discrimination climate has been conceptualized as an organizational level construct. It captures the degree to which organisational members get the impression that employees are treated differently due to their age (Kunze, Boehm, \& Bruch, 2011). Consistent with our earlier discussion, we draw on social exchange theory (Blau, 1964) and the complementary concept of perceived organisational support in order to explain the expected impact of perceived age discrimination climate on intergenerational knowledge transfer. While social exchange theory, generally refers to individuals, Eisenberger, Huntington, Hutchison, and Sowa (1986) have extended it as well to organisations. Specifically, perceived organisational support captures the degree to which employees feel supported by their organisation and, thus, will show reciprocity, for instance by providing organisational citizenship behaviours that help the organisation and co-workers (Ladd \& Henry, 2000).

So far, the majority of studies on age discrimination have focused on explicit age discrimination in the hiring or promotion process. ${ }^{5}$ Studies on age discrimination climate in everyday working life are comparatively limited (Büsch et al., 2009;

5 Note that while not directly related to interactions between organizational members, age discrimination in the hiring or promotion process may contribute to reducing intergenerational knowledge transfer through its effects on perceived age discrimination climate within the organization: If employees perceive the organization to engage in age discrimination in hiring and promotion procedures, they are likely to infer that this reflects deeply held beliefs and values of the organization in general as to older workers. 
Finkelstein \& Farrell, 2007). While age discrimination in the recruiting process may foster the emergence of an age discrimination climate, the resulting perception of age discrimination climate in everyday working life might adversely affect intergenerational knowledge transfer as well.

Based on reviewing the related literature, we expect both a direct and an indirect effect of perceived age discrimination climate on intergenerational knowledge transfer. First, we expect that perceived age discrimination climate indirectly influences intergenerational knowledge transfer through its negative impact on employee attitudes and resources which otherwise contribute positively to knowledge transfer. Specifically, age discrimination and age discrimination climate have been reported to be related to negative outcomes at the employee-level, such as reduced self-esteem (Hassell \& Perrewé, 1993), lacking perception of organizational support (Rabl, 2010), lower job satisfaction (Griffin, Bayl-Smith, \& Hesketh, 2016; Macdonald \& Levy, 2016; Redman \& Snape, 2006), reduced affective commitment (Kunze et al., 2011; Rabl \& Triana, 2013; Redman \& Snape, 2006; Snape \& Redman, 2003), and increased fear of failure (Rabl, 2010). There is substantial evidence that these factors are important predictors of knowledge transfer. For example, affective commitment increases knowledge sharing (Martin-Perez \& Martin-Cruz, 2015; Matzler \& Mueller, 2011; Matzler, Renzl, Mooradian, Krogh, \& Mueller, 2011; Swart, Kinnie, van Rossenberg, \& Yalabik, 2014; van den Hooff \& de Ridder, 2004) and knowledge seeking (Martin-Perez \& Martin-Cruz, 2015; Matzler, Renzl, Mooradian, Krogh, \& Mueller, 2011). Combining these results, studies suggest that age discrimination climate reduces important resources for intergenerational knowledge transfer and, thereby, indirectly hampers intergenerational knowledge transfer. Perceived age discrimination climate may even indirectly reduce intragenerational knowledge transfer. It was shown to reduce job satisfaction, and lower job satisfaction might reduce employees' motivation to engage in knowledge transfer of any kind.

In addition, we also anticipate a direct effect of age discrimination climate which specifically applies to intergenerational knowledge transfer only. Age discrimination is explained by differential treatment of employees due to their age (Kunze et al., 2011). This different treatment could not only manifest itself in an organisation's recruiting process, but also in a disrespectful treatment of older employees. Thus, if older employees notice a lack of support by their organisation, they may consequently reduce the sharing of knowledge. Moreover, the perception of an age discrimination climate might even spill-over to the treatment of other employees. As a consequence, in a multigenerational setting, young employees might (sub-)consciously treat older colleagues differently and might refuse to interact with them and vice versa, as they perceive such discriminatory behaviour to be approved of, either implicitly or explicitly, by the organisation. They might thus abstain from interactions that could lead to intergenerational knowledge transfer. Therefore, age discrimination might reduce intergenerational knowledge transfer as well directly. 


\section{Proposition 6: Perceived age discrimination climate within an organisation is directly and negatively related with intergenerational but not directly related with intragenerational knowledge transfer.}

\section{Network level characteristics}

Age stereotypes. The potential adverse effects of age stereotypes on intergenerational knowledge transfer can be understood by drawing on self-categorisation theory. Self-categorization theory is closely linked to self-identity theory and can be traced back to Tajfel and Turner (1986). This framework is based on the notion that individuals feel related to particular social categories, such as their age, job or gender (Turner, 1987). In order to increase their self-esteem, individuals attempt to build a positive self-concept. This process often implies an identification with peers who belong to the same category (Turner, 1987). Individuals search for advantages and positive images of their own in-group and coincidentally often devalue outgroup members (Joshi et al., 2010; Kunze et al., 2011).

Empirical evidence has supported predictions of this theoretical framework also in relation to groups identified by age as the discriminating criterion. Prior research has, for example, found that individuals who feel related to others of the same age group still often degrade members who they perceive to be substantially older or younger (Lauring \& Selmer, 2012; van Knippenberg, De Dreu, \& Homan, 2004). This process often implies age stereotyping. Integrating insights from this literature with extant research on intergenerational knowledge transfer leads us to expect that age stereotypes can harm knowledge exchange between younger and older employees.

Following the dominant view in the literature, we characterise stereotypes as "beliefs about the characteristics, attributes, and behaviours of members of certain groups" (Hilton \& Hippel, 1996, p. 240). Stereotypes do not have to be negative or positive, per se. Often, mixed stereotypes exist for the same subgroup. For example, older adults are pictured as wise but also as slow (Fiske, Cuddy, Glick, \& Xu, 2002). There is substantial empirical evidence that age stereotypes ${ }^{6}$ exist. For instance, Lester, Standifer, Schultz, and Windsor (2012), compared self-reports of employees on the values they hold and contrasted it with the ratings other individuals had about this age group. For most aspects, self-reported beliefs did not coincide with attributions.

Many scholars have looked at the explicit content of age stereotypes. The most common beliefs address older employees' presumably lower performance, slow ac-

6 In recent publications, the term ageism is often applied (e. g. Snape \& Redman, 2003). Ageism conceptualizes prejudices and potential discrimination due to age-related aspects (Kunze et al., 2011; Snape \& Redman, 2003). Ageism is stereotyping and discrimination grounded on age groups. Since ageism is not a term which is widely used in the literature on stereotypes, we keep referring to the term age stereotypes and rather than ageism. 
tions, and resistance to change (Hassell \& Perrewé, 1995; Kessler \& Staudinger, 2007; Kirchner \& Dunnette, 1954; Rosen \& Jerdee, 1977; Taylor \& Walker, 1994). These views are abundant among supervisors (Hassell \& Perrewé, 1995; Kirchner \& Dunnette, 1954; Rosen \& Jerdee, 1977), and particularly among young employees (Hassell \& Perrewé, 1995). Yet, providing additional positive jobrelated information about the employees can reduce the negative rating of older employees compared to younger employees (Finkelstein \& Burke, 1995). Interestingly, prior literature has largely studied age stereotypes towards older employees and widely neglected stereotyping younger individuals (Abrams, Eller, \& Bryant, 2006).

Drawing on stereotype threat theory, stereotypes can work as a self-fulfilling prophecy. According to stereotype threat theory, individuals who are confronted with negative stereotypes often show poorer performance (Abrams et al., 2006; Lamont, Swift, \& Abrams, 2015; Steele \& Aronson, 1995). This theory is also consistent with empirical evidence demonstrating that in particular, older individuals adjust their behaviour according to age stereotypes (Abrams et al., 2008; Hilton \& Hippel, 1996). For instance, Hess and colleagues (2004) studied the effects of stereotype priming on older adults and found that adults who were primed with age stereotypes showed inferior performance on a memory task compared to the control group.

More generally, this finding is in line with the idea that intergenerational knowledge transfer might be harmed by existing stereotypes. Older employees might (sub-)consciously adopt a negative image of themselves and show lower performance on their job in general, but also in intergenerational knowledge transfer. While we are not aware of any study that focuses on age stereotypes against younger individuals in the workplace, we suspect that younger employees may as well react to age stereotypes about older employees in terms of reducing intergenerational knowledge transfer. Theory of planned behaviour suggests that attitudes and norms influence behavioural intention and finally behaviour (Ajzen, 1991). When younger employees hold negative stereotypes about older employees (Hassell \& Perrewé, 1995), they may seek to reduce their interactions with them and, thereby, may try to avoid transferring knowledge with older employees. Indeed, there is first tentative, empirical evidence suggestive of such a relationship. Harwood and Williams (1998) implemented a scenario study and found that young participants who showed negative attitudes toward older adults in general and exhibited stronger age group identity, rated the perception of intergenerational communication more negatively. Perception of intergenerational communication, for instance, embraced satisfaction in the conversation with the depicted older person.

Overall, there is support for the existence of age stereotypes against older employees in organisations and also tentative support for a potentially damaging effect of those stereotypes on intergenerational knowledge transfer. We propose that age stereo- 
types decrease intergenerational knowledge transfer. ${ }^{7}$ Concerning intragenerational knowledge transfer, we do not expect age stereotypes to be detrimental because participants are of similar age.

Proposition 7: Age stereotypes held by individual employees are negatively related to their propensity to engage in intergenerational knowledge transfer; but unrelated to their likelihood of participating in intragenerational knowledge transfer.

Age-related conflicts. Self-categorisation theory also helps to understand how conflicts arise among employees that are heterogeneous with respect to various characteristics. Employees tend to devaluate individuals who do not belong to what they perceive as their in-group. These attitudes may impact behaviour and, thereby, might spark conflicts. This conceptual viewpoint has been supported by empirical evidence demonstrating that diversity among team members tends to lead to higher levels of conflicts compared to homogenous groups (Jehn et al., 1999; Pelled, Eisenhardt, \& Xin, 1999).

Following the approach of Jehn (1995), we distinguish between two different types of conflicts: relationship conflicts and task conflicts. Relationship conflicts refer to situations of interpersonal inharmoniousness among group members. Often, tension, hostility, and displeasure are involved. Task conflicts imply disagreements about the content of the tasks that have to be performed, such as differences in standpoints and opinions (Jehn, 1995). Evidence on the outcomes of the conflict types among team members is inconclusive (van Woerkom \& Sanders, 2010). Some studies have demonstrated that conflicts can lead to positive outcomes, as argued, for example, by Stock (2004) in her literature review. While the wide majority of studies demonstrate that in particular relationship conflicts may have potentially tremendous adverse consequences for individual and group-level variables, the effects of task conflicts are less clear. In particular, task conflicts are often considered to stimulate group performance, based on the idea that they encourage consideration of a larger range of different perspectives, thereby leading to improved quality of decision-making (Gerpott et al., 2017; Stock, 2004). However, in an extensive meta-analysis by De Dreu and Weingart (2003), relationship-based as well as taskbased conflicts, were found to decrease team member satisfaction and team performance. Also, de Wit, Greer, and Jehn (2012) came up with similar results in their meta-analysis; task and relationship conflicts were associated with negative individual and group level outcomes, such as reduced trust, lower group member commitment, and less organisational citizenship behaviours; they were positively related to counterproductive work behaviours. For example, relationship conflict was found to reduce group performance while no effect was found for the relationship between

7 Remarkably, from an outcome-focused perspective, a high frequency of intergenerational knowledge transfer might also lead to a reduction of age stereotypes (Gerpott et al., 2017; Gerpott \& Voelpel, 2014; Pettigrew \& Tropp, 2006; Williams, 1947). 
task conflict and group performance (de Wit et al., 2012). Furthermore, an oftencited study by Jehn (1995) suggested a curvilinear relationship of task conflicts for particular outcomes in non-routine task groups, such as group performance, where low levels of task conflicts would lead to low levels of group performance, and high levels of task conflicts would lead to high levels of group performance. However, potentially positive effects of task conflicts were found to apply only to non-routine groups, while in routine groups, task conflicts as well had only detrimental effects (Jehn, 1995).

Based on these findings, it could be argued that both relationship and task conflicts will negatively impact interaction among employees and, consequently, also knowledge transfer, whether of the intra- or intergenerational kind. When individuals have a dispute, disagreements exist among them. These conflicts might hinder employees to interact with each other and exchange information. Indeed, first empirical evidence suggests that conflicts, in particular, relationship conflicts, decrease knowledge sharing (Chen, 2011) and openness to share opinions (van Woerkom $\&$ Sanders, 2010). Also, both types of conflicts reduce relevant resources of employees that predict participation in knowledge transfer, such as job satisfaction (Jehn, 1995), with job satisfaction itself having been found to constitute an important predictor of knowledge transfer (de Vries et al., 2006). Overall, the evidence appears to suggest that conflicts seem to hurt the process of knowledge transfer. The detrimental effects of relationship conflict can be expected to be even stronger than those of task conflicts (de Wit et al., 2012).

Can we expect intra- or intergenerational knowledge transfer to be differently affected by such conflicts? Considering empirical evidence that age diversity leads to more conflicts and that conflicts reduce participation in knowledge transfer, we expect intergenerational knowledge transfer to be even more prone to conflict-induced derailment than intragenerational knowledge transfer: First, as argued above, age-diverse groups show higher levels of conflicts (Jehn et al., 1999; Pelled et al., 1999). Since intergenerational knowledge transfer is fundamentally characterised by two individuals who differ substantially in terms of age, prior literature point towards a higher risk of conflicts arising in inter-compared to intragenerational knowledge transfer. Second, multigenerational and lifespan theories argue that younger and older individuals hold different values. Diverging values may spark, in particular, relationship rather than task conflicts, which are arguably more harmful to knowledge transfer. Overall, in other words, we propose that interactions aiming at intergenerational knowledge transfer are more likely to be fraught with conflicts than regular knowledge transfer and that these conflicts are more likely to be relationship-based.

Proposition 8a: Interactions aiming at intergenerational knowledge transfer are more likely to exhibit conflicts than those aiming at intragenerational knowledge transfer. 


\section{Proposition 8b: Interactions aiming at intergenerational knowledge transfer are more likely to be affected by relationship conflicts than those aiming at intra- generational knowledge transfer.}

\section{Discussion and Conclusion}

The aim of this review was, first, to review existing literature on intergenerational knowledge transfer. Secondly, we aimed at integrating the literature on knowledge transfer and on age/generational diversity. Third, we developed a set of propositions based on reviewing the literature that could stimulate future empirical research. The literature on intergenerational knowledge transfer in organisations is still scarce, which was highlighted by our summary. While a substantial body of literature has examined intergenerational relationships in family contexts (e. g. Hutchison, Fox, Laas, Matharu, \& Urzi, 2010), there is a dearth of literature that focuses on the (intra-)organisational context. We first demonstrated what we actually know from studies that directly address intergenerational knowledge transfer, and then tried to fill the gaps of what makes intergenerational knowledge transfer special by integrating related literature from two streams or research, that is knowledge transfer as well as age/generational diversity. By combining insights from these three streams, we derived a set of propositions for future research based on differences between interand intragenerational knowledge transfer.

Our analysis tentatively suggests that organisational level characteristics and network characteristics might have different effects on intergenerational knowledge transfer compared to knowledge transfer between employees of a similar age. We found that social relations with respect to co-worker support appear to be more important to employees belonging to older generations. Thus, they might be even more important to sharing knowledge in intergenerational relations because these older employees are often the sending party of this information. Interestingly, trust in the communication partner might be less important since vulnerability in the intergenerational relationship may be smaller as participants are less likely to be direct competitors for positions within the organisational hierarchy. Additionally, we suggested that different obstacles to knowledge transfer prevail between different generations. For example, age difference might constitute a negative antecedent and thus function as a barrier in intergenerational knowledge transfer. Other negative antecedents, such as conflicts, may be more or less pronounced, depending on whether an interaction aims at fostering inter- or intragenerational knowledge transfer.

Therefore, we believe that our study makes two major contributions. First, we identified a lack of research in the domain of (positive and negative) antecedents to intergenerational knowledge transfer, despite the profound importance of the topic for managerial practice. While a nascent stream of studies has begun to address this issue, to the best of our knowledge, no study has, to date, investigated the question 
of whether it might be necessary to explicitly look at intergenerational knowledge transfer. By integrating two major but mostly separate research streams, we argued that we expect intergenerational knowledge transfer to function somewhat differently compared to intragenerational knowledge transfer because antecedents will pose different effects. Moreover, we formulated propositions, which can be used in future empirical studies.

Second, we also contributed to the knowledge transfer literature by highlighting the importance of distinguishing between knowledge sharing and knowledge seeking. By proposing that particular in intergenerational knowledge transfer the effects of antecedents might vary among the sender and receiver of information, we could emphasise the importance of such a distinction. Though different results can be expected, many scholars only focus on knowledge sharing and neglect knowledge seeking.

To sum up, our findings offer new insights that intergenerational knowledge transfer is indeed special. Our study suggests that generations differ across a variety of factors and that these characteristics impact positive as well as negative antecedents of intergenerational knowledge transfer. Since research on the particular topic of intergenerational knowledge transfer is still limited, our primary contribution was the integration of two different perspectives - generational diversity and knowledge transfer - by advancing propositions for future research.

\section{Limitations and Future Research}

Several limitations of this review should be noted, which, at the same time, offer directions for future research. First, although we adopted a conceptual research design based on an extensive literature review, we may still have missed studies. For example, we accessed eight databases, and therefore we may have missed relevant articles which were not available through these databases as well as unpublished studies and studies, which are currently under review. Also, we searched solely for articles published in either English or German. This is a common restriction to researchers that they are only able to tap into a pool of research published in a limited number of languages. We believe that the increasing trend to publish in English over the past few decades in combination with our research focus on a fairly novel and recent topic implies that it is unlikely that we missed out on a large body of related research, at least compared to topics that have been discussed in the literature over many decades and in many different languages. Also, by applying an additional ongoing snowball approach, we did our very best to integrate the relevant literature. Still, it constitutes a limitation of our study.

Second, many studies on knowledge transfer and generational diversity employ distinct conceptualisations of (the same or related) issues. This may have given rise to the partly inconclusive empirical results, which we represented in our review. For instance, some studies consider only the sharing of knowledge, whereas other studies include knowledge seeking as well as the sharing of knowledge, making a direct 
comparison difficult. We made an effort to clearly point out when studies only offered results on sharing and when seeking was also considered. However, not all studies made this distinction explicit; in particular, earlier literature on knowledge transfer often lacks this information.

Also, we only included antecedents that we found to have been discussed either in the empirical literature on intergenerational knowledge transfer directly, or in both of the literature on knowledge transfer and age/generational diversity (e. g. coworker support). This implies that due to our criteria for including studies, we may have missed complementary interesting antecedents, for which there is currently a lack of literature. For example, it might also be interesting to examine further the association between impersonal trust towards the organisation and intergenerational knowledge transfer (Vanhala \& Ahteela, 2011; Vanhala et al., 2011) - an issue that we, therefore, refer to future research.

Finally, we would like to emphasise that empirical research on intergenerational knowledge transfer is still scant. Integrating articles from the perspective of generational diversity and knowledge transfer has yielded propositions for future research. Future studies might test our propositions by comparing intergenerational knowledge transfer in organisations to intragenerational knowledge transfer. Additional work might also investigate a more detailed interpretation of intergenerational knowledge transfer by distinguishing between formal and informal ways of communication.

\section{References}

Abrams, D., Crisp, R. J., Marques, S., Fagg, E., Bedford, L., \& Provias, D. (2008). Threat inoculation: Experienced and imagined intergenerational contact prevents stereotype threat effects on older people's math performance. Psychology and Aging, 23(4), 934-939.

Abrams, D., Eller, A., \& Bryant, J. (2006). An age apart: The effects of intergenerational contact and stereotype threat on performance and intergroup bias. Psychology and Aging, 21(4), 691702.

Ajzen, I. (1991). The theory of planned behavior. Organizational Behavior and Human Decision Processes, 50(2), 179-211.

Alavi, M., \& Leidner, D. E. (2001). Review: Knowledge management and knowledge management systems: Conceptual foundations and research issues. MIS Quarterly, 25(1), 107-136.

Ambrosini, V., \& Bowman, C. (2001). Tacit knowledge: Some suggestions for operationalization. Journal of Management Studies, 38(6), 811-829.

Argote, L., \& Ingram, P. (2000). Knowledge transfer: A basis for competitive advantage in firms. Organizational Behavior and Human Decision Processes, 82(1), 150-169.

Argote, L., Ingram, P., Levine, J. M., \& Moreland, R. L. (2000). Knowledge transfer in organizations: Learning from the experience of others. Organizational Behavior and Human Decision Processes, 82(1), 1-8.

Arsenault, P. M. (2004). Validating generational differences. Leadership \& Organization Development Journal, 25(2), 124-141. 
Ashworth, M. J. (2006). Preserving knowledge legacies: Workforce aging, turnover and human resource issues in the US electric power industry. International Journal of Human Resource Management, 17(9), 1659-1688.

Bass, B. M., Waldman, D. A., Avolio, B. J., \& Bebb, M. (1987). Transformational leadership and the falling dominoes effect. Group \& Organization Management, 12(1), 73-87.

Beck, V. (2014). Employers' views of learning and training for an ageing workforce. Management Learning, 45(2), 200-215.

Becton, J. B., Walker, H. J., \& Jones-Farmer, A. (2014). Generational differences in workplace behavior. Journal of Applied Social Psychology, 44(3), 175-189.

Benson, J., \& Brown, M. (2011). Generations at work: Are there differences and do they matter? International Journal of Human Resource Management, 22(9), 1843-1865.

Blau, P. M. (1964). Exchange and power in social life. New York: Wiley.

Bristow, D., Amyx, D., Castleberry, S. B., \& Cochran, J. J. (2011). A cross-generational comparison of motivational factors in a sales career among Gen-X and Gen-Y college students. Journal of Personal Selling \& Sales Management, 31(1), 77-85.

Burmeister, A., \& Deller, J. (2016). Knowledge retention from older and retiring workers: What do we know, and where do we go from here? Work, Aging and Retirement, 2(2), 87-104.

Büsch, V., Dahl, S.-Å., \& Dittrich, D. A. (2009). An empirical study of age discrimination in Norway and Germany. Applied Economics, 41(5), 633-651.

Cabrera, Á., Collins, W. C., \& Salgado, J. F. (2006). Determinants of individual engagement in knowledge sharing. International Journal of Human Resource Management, 17(2), 245-264.

Cabrera, E. F., \& Cabrera, A. (2005). Fostering knowledge sharing through people management practices. International Journal of Human Resource Management, 16(5), 720-735.

Calo, T. J. (2008). Talent management in the era of the aging workforce: The critical role of knowledge transfer. Public Personnel Management, 37(4), 403-416.

Chen, Z. (2011). The interactive effects of relationship conflict, reward, and reputation on knowledge sharing. Social behavior and Personality, 39(10), 1387-1397.

Cogin, J. (2012). Are generational differences in work values fact or fiction? Multi-country evidence and implications. International Journal of Human Resource Management, 23(11), 22682294.

Collins, C. J., \& Smith, K. G. (2006). Knowledge exchange and combination: The role of human resource practices in the performance of high-technology firms. Academy of Management Journal, 49(3), 544-560.

Cook, K. S., \& Whitmeyer, J. M. (1992). Two approaches to social structure: Exchange theory and network analysis. Annual Review of Sociology, 18(1), 109-127.

Costanza, D. P., Badger, J. M., Fraser, R. L., Severt, J. B., \& Gade, P. A. (2012). Generational differences in work-related attitudes: A meta-analysis. Journal of Business and Psychology, 27(4), 375-394.

D’Amato, A., \& Herzfeldt, R. (2008). Learning orientation, organizational commitment and talent retention across generations. Journal of Managerial Psychology, 23(8), 929-953.

De Dreu, C., \& Weingart, L. R. (2003). Task versus relationship conflict, team performance, and team member satisfaction: A meta-analysis. Journal of Applied Psychology, 88(4), 741-749. 
De Long, D. W. (2004). Lost knowledge: Confronting the threat of an aging workforce. Oxford: Oxford University Press.

De Long, D. W., \& Davenport, T. 2003. Better practices for retaining organizational knowledge: Lessons from the leading edge. Employment Relations Today, 30(3), 51-63.

de Vries, R. E., van den Hooff, B., \& de Ridder, J. A. (2006). Explaining knowledge sharing: The role of team communication styles, job satisfaction, and performance beliefs. Communication Research, 33(2), 115-135.

de Wit, F. R. C., Greer, L. L., \& Jehn, K. A. (2012). The paradox of intragroup conflict: A metaanalysis. Journal of Applied Psychology, 97(2), 360-390.

Dodd, N. G., \& Ganster, D. C. (1996). The interactive effects of variety, autonomy, and feedback on attitudes and performance. Journal of Organizational Behavior, 17(4), 329-347.

Drabe, D., Hauff, S., \& Richter, N. F. (2015). Job satisfaction in aging workforces: An analysis of the USA, Japan and Germany. International Journal of Human Resource Management, 26(6), 783-805.

Eisenberger, R., Huntington, R., Hutchison, S., \& Sowa, D. (1986). Perceived organizational support. Journal of Applied Psychology, 71(3), 500-507.

Ellwart, T., Bündgens, S., \& Rack, O. (2013). Managing knowledge exchange and identification in age diverse teams. Journal of Managerial Psychology, 28(7/8), 950-972.

Finkelstein, L. M., \& Burke, M. J. (1995). Age discrimination in simulated employment contexts: An integrative analysis. Journal of Applied Psychology, 80(6), 652-663.

Finkelstein, L. M., \& Farrell, S. K. (2007). An expanded view of age bias in the workplace. In K. S. Shultz \& G. A. Adams (Eds.), Aging and work in the $21^{\text {st }}$ century (pp. 73-108). Mahwah, NJ: Lawrence Erlbaum Associates.

Fiske, S. T., Cuddy, A. J. C., Glick, P., \& Xu, J. (2002). A model of (often mixed) stereotype content: Competence and warmth respectively follow from perceived status and competition. Journal of Personality and Social Psychology, 82(6), 878-902.

Fleig-Palmer, M. M., \& Schoorman, F. D. (2011). Trust as a moderator of the relationship between mentoring and knowledge transfer. Journal of Leadership \& Organizational Studies, 18(3), $334-343$.

Foss, N. J., Minbaeva, D. B., Pedersen, T., \& Reinholt, M. (2009). Encouraging knowledge sharing among employees: How job design matters. Human Resource Management, 48(6), 871-893.

García-Morales, V. J., Lloréns-Montes, F. J., \& Verdú-Jover, A. J. (2008). The effects of transformational leadership on organizational performance through knowledge and innovation. British Journal of Management, 19(4), 299-319.

Gerpott, F. H., Lehmann-Willenbrock, N., \& Voelpel, S. 2017. A phase model of intergenerational learning in organizations. Academy of Management Learning \& Education, 16(2), 193216.

Gerpott, F. H., \& Voelpel, S. (2014). Wer lernt was von wem? Wissensaustausch in altersgemischten Lerngruppen [Who learns from whom? Knowledge exchange in age-diverse learning groups]. PERSONALquarterly, 66(3), 16-21.

Grant, R. M. (1996). Toward a knowledge-based theory of the firm. Strategic Management Journal, 17(2), 109-122. 
Griffin, B., Bayl-Smith, P., \& Hesketh, B. (2016). The longitudinal effects of perceived age discrimination on the job satisfaction and work withdrawal of older employees. Work, Aging and Retirement, 1-13.

Hackman, J. R., \& Lawler, E. E. (1971). Employee reactions to job characteristics. Journal of Applied Psychology, 55(3), 259-286.

Hackman, J. R., \& Oldham, G. R. (1976). Motivation through the design of work: Test of a theory. Organizational Behavior and Human Performance, 16(2), 250-279.

Harvey, J. (2012). Managing organizational memory with intergenerational knowledge transfer. Journal of Knowledge Management, 16(3), 400-417.

Harwood, J., \& Williams, A. (1998). Expectations for communication with positive and negative subtypes of older adults. International Journal of Aging and Human Development, 47(1), 11-33.

Hassell, B. L., \& Perrewé, P. L. (1993). An examination of the relationship between older workers' perceptions of age discrimination and employee psychological states. Journal of Managerial Issues, 5(1), 109-120.

Hassell, B. L., \& Perrewé, P. L. (1995). An examination of beliefs about older workers: Do stereotypes still exist? Journal of Organizational Behavior, 16(5), 457-468.

Hess, T. M., Hinson, J. T., \& Statham, J. A. (2004). Explicit and implicit stereotype activation effects on memory: Do age and awareness moderate the impact of priming? Psychology and Aging, 19(3), 495-505.

Hilton, J. L., \& von Hippel, W. von. (1996). Stereotypes. Annual Review of Psychology, 47(1), 237-271.

Hsu, M.-H., \& Chang, C.-M. (2014). Examining interpersonal trust as a facilitator and uncertainty as an inhibitor of intra-organisational knowledge sharing. Information Systems Journal, 24(2), 119-142.

Hutchison, P., Fox, E., Laas, A. M., Matharu, J., \& Urzi, S. (2010). Anxiety, outcome expectancies, and young people's willingness to engage in contact with the elderly. Educational Gerontology, 36(10-11), 1008-1021.

Inceoglu, I., Segers, J., \& Bartram, D. (2012). Age-related differences in work motivation. Journal of Occupational and Organizational Psychology, 85(2), 300-329.

Inceoglu, I., Segers, J., Bartram, D., \& Vloeberghs, D. (2009). Age differences in work motivation in a sample from five northern European countries. Zeitschrift für Personalpsychologie, 8(2), 59-70.

Jehn, K. A. (1995). A multimethod examination of the benefits and detriments of intragroup conflict. Administrative Science Quarterly, 40(2), 256-282.

Jehn, K. A., Northcraft, G. B., \& Neale, M. A. (1999). Why differences make a difference: A field study of diversity, conflict, and performance in workgroups. Administrative Science Quarterly, 44(4), 741-763.

Jo, S. J., \& Joo, B.-K. (2011). Knowledge sharing: The influences of learning organization culture, organizational commitment, and organizational citizenship behaviors. Journal of Leadership \& Organizational Studies, 18(3), 353-364.

Joe, C., Yoong, P., \& Patel, K. (2013). Knowledge loss when older experts leave knowledge-intensive organisations. Journal of Knowledge Management, 17(6), 913-927.

Jones, C. J., \& Meredith, W. (1996). Patterns of personality change across the lifespan. Psychology and Aging, 11(1), 57-65. 
Joshi, A., Dencker, J., Franz, G., \& Martocchio, J. (2010). Unpacking generational identities in organizations. Academy of Management Review, 35(3), 392-414.

Kankanhalli, A., Tan, B. C. Y., \& Wei, K.-K. (2005). Contributing knowledge to electronic knowledge repositories: An empirical investigation. MIS Quarterly, 29(1), 113-143.

Kessler, E.-M., \& Staudinger, U. M. 2007. Intergenerational potential: Effects of social interaction between older adults and adolescents. Psychology and Aging, 22(4), 690-704.

Kirchner, W. K., \& Dunnette, M. D. (1954). Attitudes toward older workers. Personnel Psycholo$g y, 7(2), 257-265$.

Kuhn, M., \& Hetze, P. (2009). Knowledge transfer within teams and demographic change. In M. Kuhn \& C. Ochsen (Eds.), Labour Markets and Demographic Change (pp. 148-168). Wiesbaden: VS Verlag für Sozialwissenschaften.

Kuhnert, K. W., \& Lewis, P. (1987). Transactional and transformational leadership: A constructive/developmental analysis. Academy of Management Review, 12(4), 648-657.

Kulik, C. T., Ryan, S., Harper, S., \& George, G. (2014). Aging populations and management. Academy of Management Journal, 57(4), 929-935.

Kunze, F., Boehm, S. A., \& Bruch, H. (2011). Age diversity, age discrimination climate and performance consequences - A cross organizational study. Journal of Organizational Behavior, 32(2), 264-290.

Ladd, D., \& Henry, R. A. (2000). Helping coworkers and helping the organization: The role of support perceptions, exchange ideology, and conscientiousness. Journal of Applied Social Psychology, 30(10), 2028-2049.

Lamont, R. A., Swift, H. J., \& Abrams, D. (2015). A review and meta-analysis of age-based stereotype threat: Negative stereotypes, not facts, do the damage. Psychology and Aging, 30(1), $180-193$.

Lauring, J., \& Selmer, J. (2012). Knowledge sharing in diverse organisations. Human Resource Management Journal, 22(1), 89-105.

Lee, P., Gillespie, N., Mann, L., \& Wearing, A. (2010). Leadership and trust: Their effect on knowledge sharing and team performance. Management Learning, 41(4), 473-491.

Lee, S., Yoo, Y., \& Yun, S. (2015). Sharing my knowledge?: An interactional perspective. Journal of Managerial Psychology, 30(8), 986-1002.

Lefter, V., Bratianu, C., Agapie, A., Agoston, S., \& Orzea, I. (2011). Intergenerational knowledge transfer in the academic environment of knowledge-based economy. Amfiteatru Economic, 13(30), 392-403.

Leiter, M. P., Jackson, N. J., \& Shaughnessy, K. (2009). Contrasting burnout, turnover intention, control, value congruence and knowledge sharing between Baby Boomers and Generation X. Journal of Nursing Management, 17(1), 100-109.

Lester, S. W., Standifer, R. L., Schultz, N. J., \& Windsor, J. M. (2012). Actual versus perceived generational differences at work: An empirical examination. Journal of Leadership \& Organizational Studies, 19(3), 341-354.

Levine, S. S., \& Prietula, M. J. (2012). How knowledge transfer impacts performance: A multilevel model of benefits and liabilities. Organization Science, 23(6), 1748-1766.

Levy, B. R., Pilver, C., Chung, P. H., \& Slade, M. D. (2014). Subliminal strengthening: Improving older individuals' physical function over time with an implicit-age-stereotype intervention. Psychological Science, 25(12), 2127-2135. 
Levy, M. (2011). Knowledge retention: Minimizing organizational business loss. Journal of Knowledge Management, 15(4), 582-600.

Liebowitz, J., Ayyavoo, N., Nguyen, H., Carran, D., \& Simien, J. (2007). Cross-generational knowledge flows in edge organizations. Industrial Management \& Data Systems, 107(8), 1123 1153.

Lin, C.-P. (2007). To share or not to share: Modeling tacit knowledge sharing, its mediators and antecedents. Journal of Business Ethics, 70(4), 411-428.

Liu, N. C., \& Liu, M. S. (2011). Human resource practices and individual knowledge-sharing behavior - An empirical study for Taiwanese R\&D professionals. The International Journal of Human Resource Management, 22(04), 981-997.

Liu, Y., \& DeFrank, R. S. (2013). Self-interest and knowledge-sharing intentions: The impacts of transformational leadership climate and HR practices. International Journal of Human Resource Management, 24(6), 1151-1164.

Lyons, S., \& Kuron, L. (2013). Generational differences in the workplace: A review of the evidence and directions for future research. Journal of Organizational Behavior, 35(1), 139-157.

Macdonald, J. L., \& Levy, S. R. (2016). Ageism in the workplace: The role of psychosocial factors in predicting job satisfaction, commitment, and engagement. Journal of Social Issues, 72(1), 169-190.

Macky, K., Wong, M., Gardiner, E., Lang, W., \& Coulon, L. (2008). Generational differences in personality and motivation. Do they exist and what are the implications for the workplace? Journal of Managerial Psychology, 23(8), 878-890.

Martin-Perez, V., \& Martin-Cruz, N. (2015). The mediating role of affective commitment in the rewards-knowledge transfer relation. Journal of Knowledge Management, 19(6), 1167-1185.

Matzler, K., \& Mueller, J. (2011). Antecedents of knowledge sharing - Examining the influence of learning and performance orientation. Journal of Economic Psychology, 32(3), 317-329.

Matzler, K., Renzl, B., Mooradian, T., Krogh, G. von, \& Mueller, J. (2011). Personality traits, affective commitment, documentation of knowledge, and knowledge sharing. International Journal of Human Resource Management, 22(2), 296-310.

Maurer, I., Bartsch, V., \& Ebers, M. (2011). The value of intra-organizational social capital: How it fosters knowledge transfer, innovation performance, and growth. Organization Studies, 32(2), 157-185.

McAdams, D. P., de St. Aubin, E., \& Logan, R. L. (1993). Generativity among young, midlife, and older adults. Psychology and Aging, 8(2), 221-230.

McAllister, D. J. (1995). Affect- and cognition-based trust as foundations for interpersonal cooperation in organizations. Academy of Management Journal, 38(1), 24-59.

McNichols, D. (2010). Optimal knowledge transfer methods: A Generation X perspective. Journal of Knowledge Management, 14(1), 24-37.

Milligan, S. (2014). Capturing the wisdom of four generations. Retrieved from https://www.shrm.or $\mathrm{g} /$ publications/hrmagazine/editorialcontent/2014/1114/pages/1114-intergenerational-knowled ge-transfer.aspx.

Minbaeva, D. B., \& Pedersen, T. (2010). Governing individual knowledge-sharing behaviour. International Journal of Strategic Change Management, 2(2/3), 200-222.

Mooradian, T., Renzl, B., \& Matzler, K. (2006). Who trusts? Personality, trust and knowledge sharing. Management Learning, 37(4), 523-540. 
Mueller, J. (2014). A specific knowledge culture: Cultural antecedents for knowledge sharing between project teams. European Management Journal, 32(2), 190-202.

Noethen, D. (2011). Knowledge transfer in teams and its role for the prevention of knowledge loss. Doctoral Dissertation. Jacobs University Bremen.

Noethen, D., \& Voelpel, S. (2011). Baby-Boomer-Wissen, Bye-bye?: Ein wissenschaftlicher Blick auf den intergenerationalen Wissenstransfer [Baby Boomer knowledge - Good-bye? An academic analysis of intergenerational knowledge transfer]. Ökologisches Wirtschaften, 25(2), 3942.

Nonaka, I. (1994). A dynamic theory of organizational knowledge creation. Organization Science, 5(1), 14-37.

OECD. (2014). Germany: Keeping the edge: Competitiveness for inclusive growth. Paris: OECD Publishing.

Osterloh, M., \& Frey, B. S. (2000). Motivation, knowledge transfer, and organizational forms. Organization Science, 11(5), 538-550.

Pelled, L. H., Eisenhardt, K. M., \& Xin, K. R. (1999). Exploring the black box: An analysis of work group diversity, conflict, and performance. Administrative Science Quarterly, 44(1), 1-28.

Pettigrew, T. F., \& Tropp, L. R. (2006). A meta-analytic test of intergroup contact theory. Journal of Personality and Social Psychology, 90(5), 751-783.

Pfeffer, J., \& Salancik, G. R. (1978). The external control of organizations: A resource dependence perspective. New York: Harper \& Row.

Polanyi, M. (1969). Personal knowledge: Towards a post-critical philosophy. London: Routledge \& Kegan Paul.

Prensky, M. 2001. Digital natives, digital immigrants part 1. On the Horizon, 9(5), 1-6.

Rabl, T. (2010). Age discrimination, and achievement motives. A study of German employees. Personnel Review, 39(4), 448-467.

Rabl, T., \& Triana, M. d. C. (2013). How German employees of different ages conserve resources: Perceived age discrimination and affective organizational commitment. International Journal of Human Resource Management, 24(19), 3599-3612.

Redman, T., \& Snape, E. (2006). The consequences of perceived age discrimination amongst older police officers: Is social support a buffer? British Journal of Management, 17(2), 167-175.

Renzl, B. (2008). Trust in management and knowledge sharing: The mediating effects of fear and knowledge documentation. Omega, 36(2), 206-220.

Rhodes, J., Hung, R., Lok, P., Ya-Hui Lien, B., \& Wu, C. (2008). Factors influencing organizational knowledge transfer: Implication for corporate performance. Journal of Knowledge Management, 12(3), 84-100.

Rhodes, S. R. (1983). Age-related differences in work attitudes and behavior: A review and conceptual analysis. Psychological Bulletin, 93(2), 328-367.

Richter, D. (2014). Demographic change and innovation: The ongoing challenge from the diversity of the labor force. Management Revue, 25(3), 166-184.

Robinson, R. V., \& Jackson, E. F. (2001). Is trust in others declining in America? An age-periodcohort analysis. Social Science Research, 30(1), 117-145.

Rosen, B., \& Jerdee, T. H. (1977). Too old or not too old. Harvard Business Review, 55(6), 97106. 
Schaubroeck, J., Lam, S. S. K., \& Cha, S. E. (2007). Embracing transformational leadership: Team values and the impact of leader behavior on team performance. Journal of Applied Psychology, 92(4), 1020-1030.

Schein, E. H. (1984). Coming to a new awareness of organizational culture. Sloan Management Review, 25(2), 3-16.

Schneid, M., Isidor, R., Steinmetz, H., \& Kabst, R. (2016). Age diversity and team outcomes: A quantitative review. Journal of Managerial Psychology, 31(1), 2-17.

Schwaer, C., Biemann, T., \& Voelpel, S. (2012). Antecedents of employee's preference for knowledge-sharing tools. International Journal of Human Resource Management, 23(17), 3613-3635.

Sheng, M. L., Chang, S., Teo, T., \& Lin, Y. (2013). Knowledge barriers, knowledge transfer, and innovation competitive advantage in healthcare settings. Management Decision, 51(3), 461478.

Sirias, D., Karp, H. B., \& Brotherton, T. (2007). Comparing the levels of individualism/collectivism between baby boomers and generation X. Management Research News, 30(10), 749-761.

Smircich, L. (1983). Concepts of culture and organizational analysis. Administrative Science Quarterly, 28(3), 339-358.

Smola, K. W., \& Sutton, C. D. (2002). Generational differences: Revisiting generational work values for the new millennium. Journal of Organizational Behavior, 23(4), 363-382.

Snape, E., \& Redman, T. (2003). Too old or too young? The impact of perceived age discrimination. Human Resource Management Journal, 13(1), 78-89.

Spender, J.-C. (1996). Making knowledge the basis of a dynamic theory of the firm. Strategic Management Journal, 17(S2), 45-62.

Srivastava, A., Bartol, K. M., \& Locke, E. A. (2006). Empowering leadership in management teams: Effects on knowledge sharing, efficacy, and performance. Academy of Management Journal, 49(6), 1239-1251.

Starks, A. (2013). The forthcoming generational workforce transition and rethinking organizational knowledge transfer. Journal of Intergenerational Relationships, 11(3), 223-237.

Steele, C. M., \& Aronson, J. (1995). Stereotype threat and the intellectual test performance of African Americans. Journal of Personality and Social Psychology, 69(5), 797-811.

Stock, R. (2004). Drivers of team performance: What do we know and what have we still to learn? Schmalenbach Business Review, 56(3), 274-306.

Swart, J., Kinnie, N., van Rossenberg, Y., \& Yalabik, Z. Y. (2014). Why should I share my knowledge? A multiple foci of commitment perspective. Human Resource Management Journal, 24(3), 269-289.

Swift, M. L., \& Virick, M. (2013). Perceived support, knowledge tacitness, and provider knowledge sharing. Group \& Organization Management, 38(6), 717-742.

Swift, P. E., \& Hwang, A. (2013). The impact of affective and cognitive trust on knowledge sharing and organizational learning. The Learning Organization, 20(1), 20-37.

Tajfel, H., \& Turner, J. C. (1986). The socal identity theory of intergroup behavior. In S. Worchel $\&$ W. G. Austin (Eds.), Psychology of intergroup relations (pp. 7-24). Chicago, IL: Nelson-Hall.

Taylor, P. E., \& Walker, A. 1994. The ageing workforce. Employers' attitudes towards older people. Work, Employment \& Society, 8(4), 569-591.

Tempest, S. (2003). Intergenerational learning: A reciprocal knowledge development process that challenges the language of learning. Management Learning, 34(2), 181-200. 
Trzesniewski, K. H., \& Donnellan, M. B. (2010). Rethinking "Generation Me": A study of cohort effects from 1976-2006. Perspectives on Psychological Science, 5(1), 58-75.

Turner, J. C. (1987). Rediscovering the social group: A self-categorization theory. Oxford: Blackwell.

Twenge, J. M., Campbell, S. M., Hoffman, B. J., \& Lance, C. E. (2010). Generational differences in work values: Leisure and extrinsic values increasing, social and intrinsic values decreasing. Journal of Management, 36(5), 1117-1142.

Twenge, J. M. (2010). A review of the empirical evidence on generational differences in work attitudes. Journal of Business and Psychology, 25(2), 201-210.

van den Hooff, B., \& de Ridder, J. A. (2004). Knowledge sharing in context: The influence of organizational commitment, communication climate and CMC use on knowledge sharing. Journal of Knowledge Management, 8(6), 117-130.

van Knippenberg, D., De Dreu, C., \& Homan, A. (2004). Work group diversity and group performance: An integrative model and research agenda. Journal of Applied Psychology, 89(6), $1008-1022$.

van Wijk, R., Jansen, J. J. P., \& Lyles, M. A. (2008). Inter- and intra-organizational knowledge transfer: A meta-analytic review and assessment of its antecedents and consequences. Journal of Management Studies, 45(4), 830-853.

van Woerkom, M., \& Sanders, K. (2010). The romance of learning from disagreement. The effect of cohesiveness and disagreement on knowledge sharing behavior and individual performance within teams. Journal of Business and Psychology, 25(1), 139-149.

Vanhala, M., \& Ahteela, R. (2011). The effect of HRM practices on impersonal organizational trust. Management Research Review, 34(8), 869-888.

Vanhala, M., Puumalainen, K., \& Blomqvist, K. (2011). Impersonal trust: The development of the construct and the scale. Personnel Review, 40(4), 485-513.

Vanhala, M., \& Ritala, P. (2016). HRM practices, impersonal trust and organizational innovativeness. Journal of Managerial Psychology, 31(1), 95-109.

Wang, S., \& Noe, R. A. (2010). Knowledge sharing: A review and directions for future research. Human Resource Management Review, 20(2), 115-131.

Watson, S., \& Hewett, K. (2006). A multi-theoretical model of knowledge transfer in organizations: Determinants of knowledge contribution and knowledge reuse. Journal of Management Studies, 43(3), 141-173.

Wei, J., Zheng, W., \& Zhang, M. (2011). Social capital and knowledge transfer: A multi-level analysis. Human Relations, 64(11), 1401-1423.

Wernerfelt, B. (1984). A resource-based view of the firm. Strategic Management Journal, 5(2), $171-180$.

Wilkesmann, U., Wilkesmann, M., \& Virgillito, A. (2009). The absence of cooperation is not necessarily defection: Structural and motivational constraints of knowledge transfer in a social dilemma situation. Organization Studies, 30(10), 1141-1164.

Wilkesmann, U., \& Virgillito, A. (2013). Wissenstransfer im Betriebsrat [Knowledge transfer in works councils]. Industrielle Beziehungen, 21(2), 133-158.

Williams, R. M. (1947). The reduction of intergroup tensions: A survey of research on problems of ethnic, racial, and religious group relations. New York: Social Science Research Council.

Xue, Y., Bradley, J., \& Liang, H. (2011). Team climate, empowering leadership, and knowledge sharing. Journal of Knowledge Management, 15(2), 299-312. 
Zhao, Z. J., \& Anand, J. (2009). A multilevel perspective on knowledge transfer: Evidence from the Chinese automotive industry. Strategic Management Journal, 30(9), 959-983.

\section{Appendix}

\section{Table 2: Summary of applied keywords}

\begin{tabular}{|c|c|}
\hline $\begin{array}{l}\text { Keywords related to } \\
\text { knowledge transfer in } \\
\text { general }\end{array}$ & $\begin{array}{l}\text { " "Knowledge Transfer" } \\
\text { "Knowledge Search" } \\
\text { "Knowledge Sharing" } \\
\text { " "Knowledge Exchange" }\end{array}$ \\
\hline $\begin{array}{l}\text { Keywords related to } \\
\text { intergenerational } \\
\text { knowledge transfer }\end{array}$ & 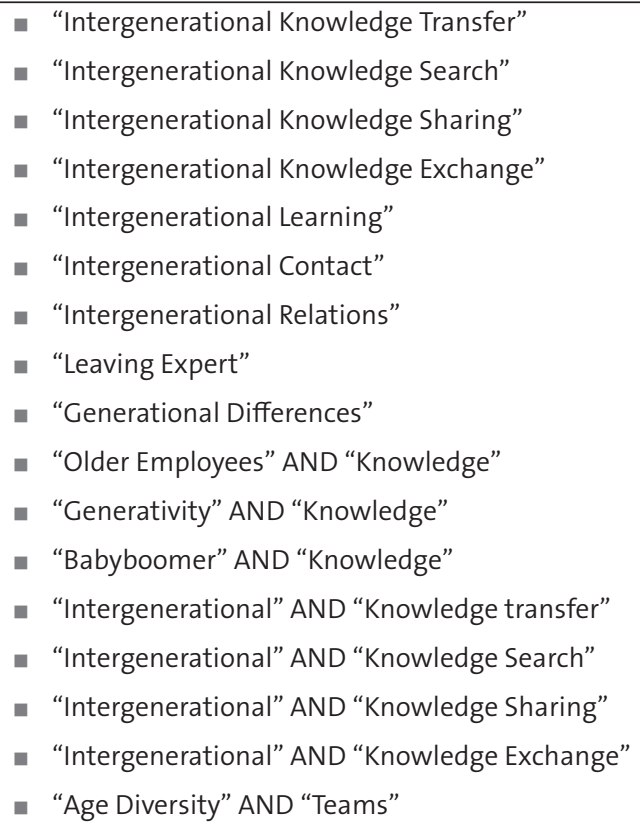 \\
\hline
\end{tabular}

